\title{
PolítICAS PÚBLICAS DE GÊNERO EM SANTA CATARINA: UMA ANÁLISE DOS CURRÍCULOS DE GRADUAÇÃO E PÓS-GRADUAÇÃO
}

\author{
Marel Eliane Graupe \\ GeRALDO Augusto LoCkS \\ Josilaine Antunes Pereira \\ Universidade do Planalto Catarinense (UNIPLAC), Lages, Santa \\ Catarina, Brasil
}

\begin{abstract}
Resumo: Este artigo refere-se a uma pesquisa realizada nas Instituições de Ensino Superior (IES) de Santa Catarina sobre a inclusão de gênero, sexualidade e diversidade na estrutura curricular de cursos de licenciatura e de pós-graduação em Educação. O referencial teórico abarca autoras (es) como Scott (1995), Louro (1997), Grossi (1998) e Beauvoir (1980). Trata-se de uma pesquisa documental numa abrangência de 167 IES, contabilizando os seus respectivos polos. Dessas instituições pesquisadas, 53 apresentam disciplina sobre o foco da pesquisa nos cursos de licenciatura e em 12 delas a temática é apresentada nos cursos de pós-graduação em Educação. Os dados demonstraram que apesar de retrocessos, como a exclusão da categoria gênero em alguns Planos Municipais, Estaduais e o Plano Nacional de Educação, da aprovação de Projetos de Lei da Escola sem Partido, a discussão de gênero e sexualidade resiste e faz-se presente significativamente nas IES no Estado de Santa Catarina (SC).
\end{abstract}

Palavras-chave: Gênero. Ensino Superior. Políticas Públicas. Estrutura Curricular.

\section{INTRODUÇÃO}

O objetivo deste artigo é analisar quais Instituições de Ensino Superior (IES) de Santa Catarina abordam as temáticas de gênero, sexualidade e diversidade nos currículos dos cursos de licenciatura e pós-graduação em educação. Na Conferência Nacional da Educação Básica (CONEB), ocorrida em 2008, foi aprovada a incorporação dos estudos de gênero e diversidade nos currículos das licenciaturas, configurando-se como um passo fundamental para a concretização da inclusão dessas temáticas na IES. Dessa forma, justifica-se a importância de mapear quais são as IES que oferecem disciplinas sobre estas temáticas em seus programas de pós-graduação em Educação e em seus cursos de licenciatura.

Os Parâmetros Curriculares Nacionais (PCN), de 1997, apontam que a escola não pode se eximir da responsabilidade que lhe cabe de discutir determinados temas, tais como as desigualdades de gênero e a diversidade sexual. Portanto, considera-se relevante pesquisar se as temáticas de gênero e diversidade são contempladas no plano Municipal 
de Educação na cidade de Lages e nos Projetos Político-Pedagógicos das escolas municipais.

A Conferência Nacional de Educação (CONAE), de 2014, abordou a temática de gênero no seu eixo dois. Também foi realizado um evento preparatório chamado Conferência Nacional Livre de Educação e Gênero, nos dias 11 e 12 de novembro de 2013, em Brasília/DF, que contou com a presença de delegadas eleitas para a CONAE, com o objetivo de preparar as pessoas para as reflexões e discussões sobre a importância da temática de gênero nas políticas públicas de educação.

Para se compreender a relevância acadêmica e social deste estudo, torna-se indispensável aprofundar conceitualmente em algumas questões do campo de gênero, sexualidade e diversidade. A historiadora estadunidense Joan Scott, em seu célebre artigo Gênero: uma categoria útil de análise histórica (1995), abalou as concepções de gênero, trazendo novas perspectivas para o estudo. Resumidamente, Joan Scott concluiu que gênero é uma percepção sobre as diferenças sexuais, hierarquizando essas diferenças dentro de uma maneira de pensar enrijecida e dualista. Scott nunca afirmou que não há diferenças entre os corpos sexuados, mas o que interessa a ela são as formas como se constroem significados culturais para essas diferenças.

Quando damos sentido para essas diferenças e, consequentemente, posicionamo-las dentro de relações hierárquicas, acabamos por criar papéis de gênero. Miriam Pillar Grossi diz:

Papéis de gênero referem-se a um conjunto de padrões e expectativas de comportamentos que são aprendidos em sociedade correspondentes aos diferentes gêneros e que conformam as identidades dos indivíduos pertencentes a esses grupos. São a manifestação social ou a representação social do que é ser macho ou fêmea, em diferentes culturas ou mesmo dentro de uma mesma cultura (GROSSI, 1998, p.2).

Um item ainda mais complexo é a chamada identidade de gênero, que se refere ao sentimento individual, ou seja, indica como o sujeito se percebe ou se reconhece como pessoa. São vários aspectos que indicam o que é considerado ser homem ou mulher. As palavras de Louro (2000) facilitam o entendimento sobre identidade:

Que identidades são, afinal, marcadas? Aquelas que são diferentes - é a resposta imediata. Mas diferentes em quê? Ou melhor, diferentes de quem? A busca da resposta obriga-nos a estabelecer algum tipo de comparação, analogia, confronto. Uma identidade é sempre, necessariamente, definida em relação à outra, depende de outra - na afirmação da identidade, inscreve-se a diferença. Contudo, ainda que o caráter relacional seja constituinte da representação de qualquer identidade, podemos notar que algumas delas ocupam, culturalmente, uma posição central e servem de referência a todas as demais. Essas identidades são representadas como "normais", básicas, hegemônicas. É por contraponto ou comparação a elas que as outras são qualificadas como diferentes (LOURO, 2000, p. 67).

A construção da identidade é relacional e construtiva, eu em relação ao outro e nós em relação a eles. Neste sentido, uma das características da identidade é revelar a 
singularidade de cada pessoa. Segundo Beauvoir (1980, p. 9) “ninguém nasce mulher, torna-se mulher", mas, dito de outra forma, a sociedade impõe padrões comportamentais para meninas e meninos desde muito cedo. Ser homem e ser mulher está condicionado ao meio sociocultural.

As autoras acima problematizam a visão biologicista da identidade de gênero, desvinculando-a da condição fisiológica ou encapsulada no sexo. Ao contrário, revelam que gênero e identidade sexual são construções socioculturais. $O$ conhecimento destes conceitos fortalece o desenvolvimento de uma cultura de respeito aos direitos humanos, para se reconhecer e respeitar diferentes identidades sexuais. Sabe-se que é a família, e mais amplamente a sociedade, que normatizam e normalizam valores, princípios, visões de mundo, padrões de comportamento. Numa sociedade cujo ethos hegemônico é o patriarcalismo, as reações de gênero são assimétricas, predominando valores masculinos sobre os femininos; do ponto de vista da sexualidade, a heterossexualidade é imposta como a única válida e reconhecida. As outras manifestações da sexualidade são rejeitadas, abominadas e excluídas. É neste contexto cultural extremamente homofóbico que entendemos o papel da educação escolar, particularmente nos espaços das Instituições de Ensino Superior formadoras de professores (as) e de outros profissionais de diferentes campos do conhecimento, formadores de opinião pública ou multiplicadores de padrões comportamentais.

A presença de disciplinas de gênero, sexualidade e diversidade nas ementas dos cursos que formarão futuros professores, e na pós-formação dos professores, são meios de evitar violência, discriminação e preconceito no meio educacional. Junqueira (2009, p.29) aborda que:

Mesmo diante da dificuldade de dissuadir racionalmente alguém embebido de ódio homofóbico, uma sociedade democrática e suas instituições (inclusive a escola) devem envidar esforços para coibir e impedir que a selvageria intolerante cause ulteriores sofrimentos e para diminuir os efeitos que ela possa ter (até mesmo na alimentação do desprezo e do ódio em relação a outros grupos) (JUNQUEIRA, 2009, p. 29).

É desejável que a disciplina gênero, sexualidade e diversidade fosse oferecida em todas as Instituições de Ensino Superior, não só do Estado de Santa Catarina, mas de todo o país, com objetivo de romper tabus, ampliar visões, desnaturalizar conceitos, problematizar atitudes e modificar comportamentos, tendo em vista a democratização das relações sociais. Afinal, o tratamento de gênero, sexualidade e diversidade não podem ser motivos de violência ou de ódio, mas de aproximação entre as pessoas, uma vez que estes conceitos expressam a condição e o desenvolvimento humano. Louro (2008, p.17) afirma que:

A construção dos gêneros e das sexualidades dá-se através de inúmeras aprendizagens e práticas, insinua-se nas mais distintas situações, é empreendida de modo explícito ou dissimulado por um conjunto inesgotável de instâncias sociais e culturais. É um processo minucioso, sutil, sempre inacabado. Família, escola, igreja, instituições legais e médicas mantêm-se, por certo, como instâncias importantes nesse processo constitutivo (LOURO, 2008, p. 17). 
A autora chama a atenção para a forma com que os educadores encaram a discussão da sexualidade, pois muitos pensam que se deixarem de tratar desses problemas a sexualidade ficará fora da escola. A escola não reproduz ou reflete as concepções de gênero e sexualidade que circulam na sociedade, mas ela própria as produz e reproduz.

Os estudos de Scott (1995) contribuem para elucidar que, quando se reflete a respeito dos papéis femininos e masculinos na sociedade, não se está colocando em oposição homens e mulheres, porém aprofundando-se a necessidade de desconstruir a supremacia do gênero masculino sobre o feminino, na direção de uma igualdade política e social, que inclui não somente o sexo, mas também a classe e a raça.

É possível observar ao longo da história da educação brasileira que principalmente as temáticas relacionadas às questões de gênero são silenciadas, ou quando aparecem têm sido relegadas ao segundo plano. Deve-se ao fato de que a sociedade brasileira historicamente desenvolveu-se sobre a matriz cultural do patriarcado. Como observa Manuel Castells:

O patriarcado caracteriza-se pela autoridade, imposta institucionalmente, do homem sobre a mulher e filhos no âmbito familiar. Para que essa autoridade possa ser exercida, é necessário que o patriarcalismo permeie toda a organização da sociedade, da produção e do consumo a política, à legislação e à cultura (CASTELLS, 2013, p. 169).

Neste contexto não se pode ignorar a relevância das políticas públicas de gênero na educação. Elas permitem a problematização de preconceitos, estereótipos e estigmas existentes no meio social escolar e não escolar. As políticas públicas são importantes para a construção de conhecimentos sobre desigualdades entre homens e mulheres e na contribuição de ações governamentais na emancipação de sujeitos e segmentos sociais discriminados e excluídos dos direitos de cidadania. Neste sentido, Bucci $(1997$, p. 94) afirma "política pública como um conjunto de ações ou normas de iniciativas governamentais, visando à concretização de direitos". Diante disso, consideramos a política pública como mecanismo que deve buscar a efetivação de direitos e reduzir as desigualdades sociais, ou seja, ajudar na construção de relações igualitárias para todas (os). Numa sociedade marcada pela desigualdade social e econômica, os segmentos sociais mais empobrecidos, também denominados de minorias, são os que mais sofrem preconceitos, estereótipos, violência e exclusão social, como negros, mulheres, LGBT, adolescentes e juventudes. Insistimos na política pública compreendida como uma ação que parte do Estado e tem como objetivo a resolução de um problema público, neste caso, a discussão de gênero e sexualidade nas IES.

Convém anotar que quando nos referimos às relações de gênero e reconhecimento de identidade sexual, no Brasil, estamos tratando de um problema público do campo dos direitos humanos a ser combatido por políticas públicas. Podemos ilustrar o caso de violência de gênero contra mulheres no espaço doméstico. A mídia nacional cotidianamente vem apontando casos de violência contra mulher, incluindo o aumento do feminicídio, pelo fato de simplesmente de ser mulher. Portanto, o tratamento dessa política não pode prescindir de sua presença no campo educacional em 
todos os níveis e modalidades de educação, mormente como diretrizes a serem assumidas por todas as Instituições de Ensino Superior nas licenciaturas e na pósgraduação em Educação.

Rosemberg (2001) ressalta a importância das políticas públicas educacionais na perspectiva da redução das desigualdades de gênero. A autora identifica que

\begin{abstract}
A produção de conhecimento sobre o atual desenvolvimento de políticas públicas de educação pela perspectiva de redução da desigualdade de gênero no sistema público de ensino brasileiro é ainda escassa e segue a tendência geral das pesquisas de gênero na educação, caracterizadas pela precária divulgação (ROSEMBERG, 2001, p. 16).
\end{abstract}

A inclusão de gênero na escola está associada à possibilidade de redução das desigualdades de gênero, do combate ao machismo, sexismo, racismo, homofobia. E para que isso ocorra, é essencial o investimento em pesquisas e na formação inicial e continuada de profissionais da educação em todos os níveis e modalidades de ensino.

Quando nos referimos à sexualidade dentro dessas temáticas pesquisadas, estamos tratando de algo além da definição de sexo. Louro (2000, p. 04), explica que a sexualidade "não é apenas uma questão pessoal, mas é social e política. A sexualidade é "aprendida", ou melhor, é construída, ao longo de toda a vida, de muitos modos, por todos os sujeitos". Ainda nas palavras de Louro (2000, p. 06):

[..] a sexualidade envolve rituais, linguagens, fantasias, representações, símbolos, convenções... Processos profundamente culturais e plurais. Nessa perspectiva, nada há de exclusivamente "natural" nesse terreno, a começar pela própria concepção de corpo, ou mesmo de natureza (LOURO, 2000, p. 06).

Nas questões curriculares, as relações de gênero são cruciais para determinar as relações de poder e o interesse, pois tanto a educação em particular como a cultura em geral se envolvem em processos de contínua transformação da identidade e da subjetividade. Louro (2000) estabelece ainda algumas distinções entre gênero e sexualidade, ou entre identidades de gênero e identidades sexuais. Expõe que a sexualidade não é exclusivamente domínio corporal, e a sua compreensão torna-se impossível se apenas se observarem os componentes naturais.

Compreender os estereótipos de gênero como produtos de uma construção histórica e cultural possibilita a desnaturalização dessas situações e a ação consciente e ativa na desconstrução dessa realidade. A educação como espaço de reflexão e de problematização da realidade pode vir a ser um importante instrumento de enfrentamento das diversas desigualdades às quais as mulheres estão submetidas.

Prezar pela diversidade na educação significa lutar pela liberdade democrática de toda a comunidade escolar ou acadêmica. As redes de ensino devem ser pioneiras no respeito à individualidade. Gomes (1998, p 16) pondera que "Entre preconceitos e discriminações, cabe à escola pública o importante papel de proporcionar a seus alunos um modelo de tolerância a ser aplicado na sociedade". O pensamento de Junqueira (2009, p.36) é adequado para se pensar o papel da escola no enfrentamento das violências: 
[...] a escola é um espaço no interior do qual e a partir do qual podem ser construídos novos padrões de aprendizado, convivência, produção e transmissão de conhecimento, sobretudo se forem ali subvertidos ou abalados valores, crenças, representações e práticas associados a preconceitos, discriminações e violências de ordem racista, sexista, misógina e homofóbica (JUNQUEIRA, 2009, p. 36).

Quando se discute gênero e diversidade não se pode ignorar as situações de violência também no cenário da educação formal. A temática sobre violência é um problema social que está presente dentro e fora das escolas, e se manifesta de diversas formas entre todos os envolvidos no processo educativo. Com a discussão sobre as diferentes formas de violência, bullying, busca-se discutir o papel da educação na produção das desigualdades.

Também visa refletir sobre a cultura da violência, especialmente na constituição das masculinidades, gerando comportamentos machistas, sexistas e homofóbicos, objetivando a desconstrução da ideia de uma essência ou natureza que explique e justifique as violências, as desigualdades de gênero, ações discriminatórias, bem como as desigualdades estabelecidas entre os vários grupos sociais em função das identidades sexuais que fogem aos padrões considerados hegemônicos e normatizados.

As Instituições de Ensino Superior e o fomento à pesquisa, originários da proliferação de cursos de graduação a partir dos anos 1990, contribuíram consideravelmente para que estudos bibliográficos e pesquisas de campo colocassem em destaque tanto a necessidade de se compreender a complexidade do que significa gênero quanto a importância desse tema no desenvolvimento de políticas públicas educacionais. Para Vianna e Unbehaum:

O intervalo que vai de 1998 a 2002 [...] documentos constituem um campo variado de estudos, desde a estrutura curricular, financiamento da educação, avaliação de desempenho e fluxo escolar, formação docente e também aspectos específicos como gênero, raça e direitos humanos. [...] a intersecção das relações de gênero e educação ganhou maior visibilidade nas pesquisas educacionais somente em meados dos anos 1990, com grandes avanços na sistematização de reivindicações que visam à superação, no âmbito do Estado e das políticas públicas, de uma série de medidas contra a discriminação da mulher. Tais medidas se revelam, porém, plenas de contradições entre a defesa da ampliação dos direitos e a ótica da restrição do papel do Estado nas políticas públicas sociais, entre elas a educação (VIANA UNBEHAUM, 2004, p. 2).

Nesse recorte histórico, as autoras destacam que a ótica de gênero vem ao encontro de mudanças na educação e na formação das (os) professoras (es), ganhando ênfase por meio de pesquisas educacionais e no campo das políticas públicas de educação. O debate de equidade de gênero propicia o entendimento de que a igualdade de direitos considera as diferenças entre os sexos, mas não entende o fazer dessas diferenças um motivo para a continuidade das desigualdades, condição que tem sido comum em diversos segmentos sociais, com aumento de casos de homofobia nas ruas, agressões em escolas, repúdio por parte de segmentos religiosos e omissão do Estado quanto à abordagem das questões de gênero nas escolas, no sentido de promover a aceitação da diferença como 
parte do ser humano e que a liberdade de escolha é um direito legal de todo cidadão brasileiro.

Indicamos a seguir algumas ameaças e transitamos pelos avanços e retrocessos que observamos nas políticas educacionais, no que concerne ao campo de gênero e diversidade sexual. No Brasil, em alguns Estados e Municípios, foi excluída a pauta de gênero e sexualidade dos planos de educação, e isto fere o direito dos sujeitos, pois os conceitos de gênero e sexualidade são essenciais para a construção de uma educação equitativa.

Mais recentemente, a mídia nacional passou a veicular matérias sobre o Programa Escola sem Partido, cujo objetivo é restringir a função do professor educador a um repassador de informações. Este Programa propõe a aprovação de leis em âmbito nacional, estadual e municipal que proíbem aos professores serem reflexivos e críticos nos seus processos de ensino e aprendizagem. Segundo a Presidente da Associação Nacional de Pós-Graduação e Pesquisa em Educação, os defensores do Programa Escola sem Partido objetivam "[...] influenciar o legislativo para que sejam formulados projetos de lei de cerceamento da liberdade de ensinar e de livre expressão, sob o pretexto de combater pretensa doutrinação ideológica que estaria ocorrendo nas escolas brasileiras" (ANPED, 2016, s/p).

Além da ideologia da Escola Sem Partido, que desde 2004 está sendo difundida no Brasil, e, especialmente pelo coordenador do site "Programa Escola Sem Partido", Miguel Nagib, destaca-se o movimento "Ideologia de Gênero".

Em meados de 2014, no período de aprovação do Plano Nacional de Educação e dos Planos estaduais e municipais no ano de 2015, emergiram diversos movimentos, organizados por representantes de grupos fundamentalistas, sustentando a exclusão da categoria gênero nesses documentos. Esse discurso de ideologia de gênero embasado em argumentos religiosos buscou convencer as autoridades públicas e a sociedade em geral de que a inclusão das categorias de gênero e sexualidade nos planos educacionais representariam "uma ameaça à família e às crianças".

Cabe ressaltar que a discussão de gênero consta, como política estadual de formação inicial e continuada, no Plano Estadual de Educação, na meta 15, na sua estratégia 13: "Implantar programas de formação dos profissionais da educação, sobre gênero, identidade de gênero, sexualidades, orientação sexual, educação ambiental e educação especial, para a promoção e efetivação dos direitos sociais" (SANTA CATARINA, 2015, p. 133).

Ainda no Plano Estadual de Santa Catarina, a meta 14, sobre os Cursos de PósGraduação em nível de Mestrado e de Doutorado, enfatiza na estratégia 9 a importância da discussão de gênero:

Estimular estudos e pesquisas em direitos humanos e inclusão, sobre gênero, orientação sexual e identidade de gênero, diversidade religiosa, relações étnicoraciais, educação ambiental, tecnologia assistiva, pedagogia da alternância, quilombola, indígena, povos do campo, comunidades tradicionais, para pessoas, público da educação especial, e em situação de privação de liberdade (grifos nossos) (SANTA CATARINA, 2015, p. 131).

Observamos que o Plano Estadual de Educação contempla, em algumas metas e estratégias, a discussão de gênero, constituindo-se em uma política pública importante 
para a implementação dessa discussão no cotidiano escolar. Entretanto, no Plano Nacional de Educação a temática de gênero e sexualidade foi suprimida.

Além do Plano Estadual de Educação de Santa Catarina, podemos citar a Proposta Curricular de Santa Catarina (2014), que é um documento norteador do trabalho pedagógico. Cabe aqui ressaltar que as diretrizes estabelecidas pela Secretaria Estadual na Proposta Curricular demonstram a preocupação no desenvolvimento, reconhecimento da (o) educanda (o) nas condições de um sujeito histórico, cidadã/cidadão pleno de direitos e deveres. Este documento enfatiza a relevância da discussão de gênero e sexualidade na formação de professoras (es) e na prática pedagógica. Enfim, as temáticas de gênero, sexualidade e diversidade na educação escolar brasileira encontram-se em disputa acirrada pela sua erradicação ou permanência.

\section{Metodologia da pesquisa e apresentação de resultados}

Os dados de campo foram obtidos pela internet, através dos sites das Instituições de Ensino Superior. A pesquisa foi dividida em duas partes para facilitar a constatação de dados: de um lado ficaram as Universidades (para uma Instituição de Ensino Superior ser considerada Universidade é necessário oferecerem atividades de ensino, de pesquisa e de extensão, que são serviços de atendimento à comunidade, nas diversas áreas do saber) de Santa Catarina, e no outro lado todas as Instituições de Ensino Superior de Santa Catarina que não são consideradas Universidades (Faculdades, Institutos, Centros Universitários e etc.). A Quantidade de Instituições e suas titulações foram obtidas no site do MEC - Ministério da Educação ${ }^{1}$ e no Portal da Educação da Secretaria de Estado da Educação de Santa Catarina².

A pesquisa é de caráter documental. Sobre a pesquisa documental podemos dizer que a técnica documental se vale de documentos originais, que ainda não receberam tratamento analítico por nenhum autor. Neste caso pesquisamos nas Estruturas Curriculares das Instituições de Ensino. Segundo Pimentel.

Com o intuito de contribuir para a utilização da análise documental em pesquisa esse texto apresenta o processo de uma investigação. [...] São descritos os instrumentos e meios de realização da análise de conteúdo, apontando o percurso em que as decisões foram sendo tomadas quanto às técnicas de manuseio de documentos: desde a organização e classificação do material até a elaboração das categorias de análise (PIMENTEL, 2001, p.179).

O uso da pesquisa documental nos permitiu conhecer se as políticas públicas no campo dos estudos de gênero, sexualidade e diversidade estão sendo implantados na formação de professoras/es e no cotidiano das Instituições de Ensino Superior de Santa Catarina.

No total foram 167 (cento e sessenta e sete) Instituições de Ensino Superior pesquisadas, contando os polos localizados em diversas cidades. Das 167 Instituições, 03 (três) são federais (e cinco polos), 153 (cento e cinquenta e três) são privadas, 01 (uma) é municipal, 01 estadual (e 3 polos da mesma) e 09 (nove) comunitárias. Embora os sites de 
31 (trinta e uma) Instituições não estarem disponíveis ou não serem encontrados, conseguimos realizar a pesquisa com êxito. Os resultados foram os seguintes:

- 87 (oitenta e sete) das Instituições de Ensino Superior oferecem licenciaturas. Cursos de Pedagogia, Letras, Artes Visuais, Geografia e História foram os mais encontrados.

- 53 (cinquenta e três) delas disponibilizavam disciplinas de gênero, sexualidade, diversidade ou cultura na ementa dos cursos de licenciatura. Disciplinas intituladas como "Corpo, Gênero e Sexualidades"; "Multiculturalismo, Sexualidade e gênero"; "Inclusão e Diversidade" e; "Antropologia Social e Cultural” foram as mais utilizadas nas grades curriculares.

- Na pesquisa sobre Pós-Graduação em Educação, 71 (setenta e uma) das Instituições ofereciam-nas. Cursos de Gestão Escolar, Educação Especial, Atendimento Educacional Especializado, por exemplo.

- Apenas 12 (doze) desses cursos oferecem disciplina sobre gênero, cultura ou sexualidade na estrutura curricular dos cursos de Gestão Escolar: Diversidade e Inclusão Educacional, Sexualidade e educação Especial e etc.

Em relação à pesquisa realizada em Universidades públicas e privadas de Santa Catarina constatou-se que há, na maioria das universidades, temas que se referem a gênero, sexualidade, cultura e diversidade. Na Universidade Federal de Santa Catarina, nos cursos de Ciências Sociais, Pedagogia, Letras - Português e História, há as disciplinas: "Gênero e Sexualidade"; "Seminários Temáticos sobre Gênero"; "Corpo, Gênero e Sexualidade"; "Educação Sexual e Alteridade"; "Sociedade, Saúde e Violência"; "Políticas Públicas e Serviço Social", "Criatividade e Discussões de Gênero"; "Gênero, Identidade, Etnias e Representações" e, por último, "Laboratório de Estudo de Gênero e História", respectivamente, na maioria delas a disciplina é obrigatória. A Universidade do Estado de Santa Catarina tem, apenas no curso de História, a disciplina relativa à pesquisa. $\mathrm{Na}$ Universidade Federal da Fronteira Sul, o curso de Ciências Sociais apresenta a disciplina de "Relações de Gênero".

Quando tomado como base as universidades particulares e comunitárias, na Universidade do Extremo Sul de Santa Catarina identifica-se a disciplina de "Educação para a Diversidade", no curso de Pedagogia, com dois créditos e optativa. Na Fundação Universidade Regional de Blumenau, os cursos de Ciências Sociais e História oferecem as disciplinas "Etnicidade e Relações de Gênero" e "História e Relações de Gênero", periodicamente. A Universidade do Sul de Santa Catarina contém em seu curso de Pedagogia a disciplina intitulada "Sexualidade e Orientação Sexual: educação, cultura e transformação social", com dois créditos e obrigatória. Já na Universidade do Planalto Catarinense foi possível encontrar em cursos como: Educação Especial, Educação Física, Geografia, História, Letras, Matemática, Música, Pedagogia e Química, a disciplina "Cultura, Diferença e Educação", de dois e quatro créditos, todas obrigatórias. As Universidades que não continham, em nenhum de seus cursos, alguma dessas disciplinas são: A Universidade do Alto Vale do Itajaí, Universidade do Oeste de Santa Catarina, Universidade Comunitária Regional de Chapecó, Universidade da Região de Joinville. 
Quando pesquisadas as pós-graduações, foi encontrado apenas na Universidade Federal de Santa Catarina, nas pós-graduações de Ciências Humanas, com a disciplina "Seminários Temáticos Sobre Gênero", quatro créditos e obrigatória. E na pós-graduação em Educação, na ementa há a disciplina de "Educação Sexual e a Alteridade", com dois créditos e é obrigatória.

\section{CONSIDERAÇÕES FINAIS}

Os resultados obtidos na pesquisa sobre a inserção das disciplinas que consideram gênero, sexualidade e diversidade nos cursos de licenciatura e pós-graduação das Instituições de Ensino Superior no Estado de Santa Catarina, foram positivos, pois a temática de gênero vem sendo abordada atendendo as políticas públicas neste campo do conhecimento. No entanto, há um ponto crucial na questão, pois não obstante a pesquisa constar gênero, sexualidade, diversidade e cultura nas disciplinas que compõem a Estrutura Curricular dos cursos, não significa que esses temas sejam realmente trabalhados ou que são trabalhados de forma efetiva.

Ainda se especula muito sobre a função dos estudos de gênero, sexualidade e diversidade, pois como constatamos ao longo desta reflexão, o ambiente escolar ou acadêmico encontra-se inserido num contexto sociocultural extremamente homofóbico, machista, racista, sexista, cercado de preconceitos, exclusões, disciplinador e normatizador de padrões comportamentais. Concebe hegemonicamente o conceito de gênero ou sexualidade encapsulado no sexo e a heterossexualidade como padrão único, reconhecida como verdade a ser reproduzida. Desse contexto surgem os movimentos de resistência, de ameaça, atingindo inclusive a construção ou desconstrução de políticas educacionais afirmativas do campo de gênero, sexualidade e diversidade. Essa realidade impacta nos Planos Municipais, Estaduais e Nacional das escolas e das Instituições de Ensino Superior, um campo de disputa em afirmar ou negar esse conhecimento.

A pesquisa permitiu identificar, ainda, a existência de disciplinas que têm por foco o conhecimento de gênero, sexualidade e diversidade em expressivo número nas Instituições de Ensino Superior no Estado de Santa Catarina. No entanto, esse dado revelou, subliminarmente, um nível de consciência de parte de coordenadores de curso e de professores, com a disposição de incluir essas temáticas nas estruturas curriculares: consciência ou exigência legal? É sabido que quando ocorre uma avaliação de curso ou da instituição, os itens das diretrizes curriculares obrigatórias estão na mira dos avaliadores do Ministério da Educação. Pontuar é preciso! Mas basta uma reflexão crítica para interrogar sobre se a prática pedagógica é concernente ou não às políticas públicas institucionalizadas.

Enfim, é importante a inserção dessas temáticas nas Instituições de Ensino Superior porque foram, historicamente, as reprodutoras das desigualdades de gênero, demarcadas por relações sociais etnocêntricas, discriminatórias e excludentes, sexistas, racistas, onde o direito à diferença, à diversidade cultural, ainda não foi reconhecido $\mathrm{e}$ concretizado. A democracia integral requer uma educação que considere relações equitativas de gênero, o reconhecimento da pluralidade cultural, enfim, a realização dos 
direitos humanos na sua integralidade e universalidade. Não obstante a pesquisa demonstrar a inserção das temáticas de gênero, sexualidade e diversidade no currículo dos cursos de licenciaturas e na pós-graduação da maioria das Instituições de Ensino Superior de Santa Catarina, essas permanecem em débito com a sociedade reprodutora do machismo, sexismo e outras expressões de preconceito, e portanto, desafiadas a romperem a lógica do desrespeito aos direitos humanos e a promoverem uma sociedade multicultural, de respeito às identidades de gênero, sexualidades e à diversidade.

Artigo recebido em: 25/08/2017

Aprovado para publicação em: 14/12/2017

\section{GENDER PUBLIC POLICIES IN SANTA CATARINA: AN ANALYSIS OF GRADUATION AND POSTGRADUATE CURRICULUMS}

ABSTRACT: This article refers to a research carried out in the Higher Education Institutions (HEI) of Santa Catarina about gender inclusion, sexuality and diversity in the curricular structure of undergraduate and postgraduate courses in Education. The theoretical reference covers authors such as Scott (1995), Louro (1997), Grossi (1998) and Beauvoir (1980). It is a documentary research with an amount of $167 \mathrm{HEl}$, accounting their respective poles. Of these Institutions surveyed, 53 presented discipline on the focus of the research in degree courses and in 12 of them the theme is presented in the post-graduation courses in Education. The data showed that, in despite of regressions such as the exclusion of the gender category in some Municipal and State Plans, and in the National Education Plan, the approval of Non-Party School Projects, the discussion of gender and sexuality resists and it is significantly present in the IES in the Santa Catarina State.

KEYWORDS: Gender. Higher education. Public policy. Curricular structure.

\section{POLÍTICAS PÚBLICAS DE GÉNERO EN SANTA CATARINA: UN ANÁLISIS DE LOS CURRÍCULOS DE GRADUACIÓN Y POSGRADO}

RESUMEN: Este artículo se refiere a una investigación realizada en las Instituciones de Enseñanza Superior (IES) de Santa Catarina sobre la inclusión de género, sexualidad y diversidad en la estructura curricular de cursos de cicenciaturas y de postgrado en Educación. El referencial teórico abarca a los autores como Scott (1995), Louro (1997), Grossi (1998) y Beauvoir (1980). Se trata de una investigación documental en un total de 167 IES, contabilizando sus respectivos polos. De estas Instituciones encuestadas, 53 presentan disciplina sobre el foco de la investigación en los cursos de licenciatura y en 12 de ellas la temática es presentada en los cursos de postgrado en Educación. Los datos muestran que, a pesar de retrocesos como la exclusión de la categoría género en algunos Planes Municipales, Estatales y el Nacional de Educación, de la aprobación de Proyectos de Ley de la Escuela sin Partido, la discusión de género y sexualidad se resiste y se hace presente significativamente em las IES en el Estado de Santa Catarina (SC).

PALABRAS CLAVE: Políticas Públicas. Actores sociales. Ideología de género. Escuela sin partido.

NOTAS: 
Políticas públicas de gênero em Santa Catarina...

1) Disponível: http://emec.mec.gov.br/. Acesso em: 08 de agosto de 2017.

2) Disponível em: serieweb.sed.sc.gov.br/cadiesportal.aspx). Acesso em: 08 de agosto de 2017.

REFERÊNCIAS

ANPED. Escola Sem Partido (2016). Ofício ANPED n 31/2016, Rio de Janeiro, 30 de maio de 2016. Disponível em: <http://www.anped.org.br/news/carta-da-presidente-daanped-aos-deputados-federais-sobre-o-seminario-da-bncc>. Acesso em: 05 out. 2016.

BRASIL. Ministério da Educação. Fórum Nacional de Educação. Conae 2014: Documento Referência. Brasília: Ministério da Educação, Secretaria Executiva Adjunta, 2013. Disponível em: $<$ http://conae2014.mec.gov.br/images/pdf/doc_referencia.pdf $>$. Acesso em: 25 jun. 2017.

BRASIL. Planejando a Próxima Década. Conhecendo as 20 metas do Plano Nacional de Educação/2014. Disponível em: <http://pne.mec.gov.br/pdf/pne_ conhecendo_20_metas.pdf >. Acesso em: 12 ago. 2017.

BRASIL. Secretaria de Educação Fundamental. Parâmetros curriculares nacionais. introdução aos parâmetros curriculares nacionais. Brasília: MEC/SEF, 1997.

BEAUVOIR, S. O Segundo Sexo: a experiência vivida. Rio de Janeiro: Nova Fronteira.

BUCCI, M. P. D. Direito administrativo e políticas públicas. Revista de informação Legislativa, Brasília, a. 34, n. 133, p. 89-98, jan./mar., 1997.

CASTELLS, M. O poder da Identidade. Tradução de Klauss Brandini Geshardin. São Paulo: Paz e Terra, 2013.

JUNQUEIRA, R. D. (org.). Diversidade Sexual na Educação: problematizações sobre a homofobia nas escolas. Brasília: Ministério da Educação, Secretaria de Educação Continuada, Alfabetização e Diversidade, UNESCO, 2009.

GROSSI, M. Identidade de Gênero e Sexualidade. Antropologia em Primeira Mão, n. 24, PPGAS/UFSC, Florianópolis, 1998.

LOURO, G. L. O Corpo Educado. Pedagogias da sexualidade. 2a edição. Editora: autêntica, 2000. 
GRAUPE, M. E.; LOCKS, G. A.; PEREIRA, J. A.

Vozes, 1997.

Gênero, sexualidade e educação. Uma perspectiva pós-estruturalista. Editora:

. Um corpo estranho: ensaios sobre sexualidade e teoria queer. 1. ed. 1. reimp. Belo Horizonte, 2008.

PIMENTEL, A. O método da análise documental: seu uso numa pesquisa histórica. Cadernos de Pesquisa, n.114, p.179-195, nov., 2001.

SANTA CATARINA. Plano Estadual de Educação de Santa Catarina. Florianópolis: SEEl, 2015. Disponível em: <http://www.sed.sc.gov.br/index.php/documentos/planoestadual-de-educacao-sc-452>. Acesso em: 05 out. 2016.

SCOTT, J. Gênero: uma categoria útil de análise. Educação e Realidade, Porto Alegre, v. 20, n. 2, p. 71-100, jul./dez. 1995.

VIANNA, C. P.; UNBEHAUM, S. O Gênero nas Políticas de Educação no Brasil: 1988-2002. Cadernos de Pesquisa, v. 34, n. 121, jan./abr. 2004. Disponível em: <http://www.scielo.br/pdf/cp/v34n121/a05n121.pdf>. Acesso em: 01 de março de 2017.

Marel Eliane Graupe: Professora do Programa de Pós-Graduação em Educação na UNIPLAC/SC. Coordena o grupo de pesquisa Gênero, Educação e Cidadania na América Latina (GECAL/UNIPLAC). Possui graduação em Pedagogia pela Universidade Regional do Noroeste do Estado do Rio Grande do Sul (2001), mestrado em Educação nas Ciências pela Universidade Regional do Noroeste do Estado do Rio Grande do Sul (2004), doutorado em Educação e Cultura pela Universidade de Osnabrueck, Alemanha (2010), revalidação UFSM (2010). Pós-doutorado Interdisciplinar em Ciências Humanas, UFSC (2011), pós-doutorado em Antropologia Social, UFSC (2012).

E-mail: marelieliane@gmail.com

Geraldo Augusto Locks: Possui graduação em Ciências Sociais pela Universidade do Planalto Catarinense (1977). Graduação em Teologia pelo Instituto de Teologia e Pastoral de Passo Fundo (1994). Mestrado em Antropologia Social pela Universidade Federal de Santa Catarina (1998). Doutorado em Antropologia Social pela Universidade Federal de Santa Catarina (2008), Pos-Doutorado pelo Programa de Pós-Graduação em Educação da Universidade Federal de Santa Catarina (2012). Atualmente é Docente Pesquisador do PPGE da Universidade do Planalto Catarinense (UNIPLAC - SC). Tecnológica de Cooperativas Populares da Universidade do Planalto Catarinense (ITCP UNIPLAC).

E-mail:seraldolocks@smail.com

Josilaine Antunes Pereira: Doutoranda em Educação (UNISINOS). Mestre em Educação (UNIPLAC - 2008). Graduada em Pedagogia (FACVEST - 2004). Especialista em Prática Escolar Numa Visão Psicopedagógica (FACVEST - 2004). 
Políticas públicas de gênero em Santa Catarina...

Conselheira Estadual dos Direitos da Criança e do Adolescente (CEDCA) - Biênio 20102012. Membro dos Grupos de Pesquisa: 1) Gênero, Educação e Cidadania na América Latina: aproximações e desatios (GECAL) e 2) Grupo de pesquisa em Educação e Desenvolvimento Territorial: políticas e práticas? (GEDETER), ambos respectivamente financiados pela Fundação de Amparo à Pesquisa e Inovação do Estado de Santa Catarina (FAPESC) e CNPq/SENAES. Conselheira do Conselho Municipal de Economia Solidária (CMES - 2017-2019), Conselheira do Conselho Municipal de Segurança Alimentar (CONSEA- 2017-2019) Conselheira Municipal dos Direitos da Mulher (CMDM 2016 - 2018).

E-mail: antunesjo@hotmail.com 